\title{
On Arguments from Ignorance
}

\section{MARTin Hinton}

University of Łódź

Department of English and General Linguistics

Łódź, Poland

mdhinton@tlen.pl

\begin{abstract}
The purpose of this paper is twofold: to give a good account of the argument from ignorance, with a presumptive argumentation scheme, and to raise issues on the work of Walton, the nature of abduction and the concept of epistemic closure. First, I offer a brief disambiguation of how the terms 'argument from ignorance' and 'argumentum ad ignorantiam' are used. Second, I show how attempts to embellish this form of reasoning by Douglas Walton and A.J. Kreider have been unnecessary and unhelpful. Lastly, I offer a full and effective account of the argument from ignorance and discuss the lessons of the analysis.
\end{abstract}

Résumé: Le but de cet article est double: donner un bon compte rendu de l'argument par l'ignorance, avec un schème d'argumentation présomptif, et soulever des questions sur certains aspects de l'œuvre de Walton, la nature des raisonnements abductifs et le concept de fermeture épistémique. Premièrement, j'offre une brève désambiguïsation de la façon dont les termes «argument par l'ignorance» et «argumentum ad ignorantiam» sont utilisés. Deuxièmement, je montre comment les tentatives de Douglas Walton et de A.J. Kreider d'embellir cette forme de raisonnement ont été ni nécessaires et ni utiles. Enfin, j'offre un compte-rendu complet et utile de l'argument par l'ignorance et je discute des leçons de l'analyse

Keywords: argument from ignorance; argumentation scheme; Kreider; Walton

\section{Introduction}

The argument from ignorance, or argumentum ad ignorantiam, itself needs little introduction. Much has been written about it, and it is an argument form which has long featured in lists of fallacies and has also been comfortably assimilated into the group of arguments which may be considered deductively fallacious but are accepted as presumptively valid at times and certainly commonly used. 
This paper will attempt to provide a good account of the argument as a decent form of practical reasoning, and in so doing criticise the accounts offered by Douglas Walton and A.J, Kreider. Of equal importance, however, certain points will be raised by the discussion as to the overall nature of Walton's account of presumptive schemes, the concept of epistemic closure, and the misuse of the concept of "abductive reasoning".

\section{Disambiguation}

Whilst these differences have been noted and commented upon many times, it is worth exposing once more the ambiguity in the usage of the term 'argument from ignorance', or sometimes 'appeal to ignorance', as a useful prelude to the arguments to come. The name is used to refer to at least three very different types of reasoning, and confusion amongst these types leads to confusion in the understanding and explanation offered in the literature, making universally applicable rules relating to such arguments impossible to construct. It will also be seen that even within the categories of use identified, a subtle equivocation on the meaning of ignorance may lead to further difficulties.

Let us begin by looking at some standard definitions. In their well-known logic textbook, Copi and Cohen define an argument from ignorance as one where it is claimed "a proposition is true simply on the basis that it has not been proved false" (1990, pp. 93), while for Zarefsky: "Appeals to ignorance assume that a claim must be true (or false) because the opposite position cannot be disproved (or proved)" (2005, pp. 84). Zarefsky, obviously, has his "proved" and "disproved" the wrong way round here, but the only real difference between the definitions, at first sight, is that the first has, we assume $p$ because not $p$ has not been proved, and the second, because not $p$ cannot be proved. Either way, there is no proof for not $p$, so $p$. Closer inspection, however, reveals that the two definitions refer to quite different arguments. In Copi and Cohen's version, the arguer claims that $p$ is true, in Zarefsky's, that we can assume $p$ to be true. This distinction reveals two of the very different uses of the term ad ignorantiam. As defined by Copi and Cohen, the argument is a deductive fallacy, since it can never be 
shown that a lack of evidence against a proposition proves its truth deductively. In informal logic, however, reasoning moves outside of what is deductively provable into what is reasonably arguable: on Zarefsky's definition, the argumentum ad ignorantiam may, or may not, be a good argument, even if it is not a deductively conclusive one. Showing when it may reasonably be used is the real challenge and one that is addressed in the sections below. The standard definitions, then, may mask the two different uses of the term: one as a logical fallacy, and the other a type of defeasible reasoning.

These two applications can both be contrasted with the term as defined by John Locke. Locke's description of the so-called "ad fallacies" in his Essay Concerning Human Understanding (1690) is well-known. However, just like the others, ad hominem and ad verecundiam, argumentum ad ignorantiam has taken on a very different meaning in modern fallacy lists. ${ }^{1}$ As Christopher Tindale has noted, "contemporary writers are at a loss to see the connections between modern treatments and what Locke has said" (2007, pp. 117). Since Locke dedicated but one sentence to its definition, there is no obstacle to supplying his version in full:

Secondly, Another way that Men ordinarily use to drive others and force them to submit to their Judgments, and receive the Opinion in debate, is to require the Adversary to admit what they allege as a Proof, or to assign a better. And this I call argumentum ad ignorantiam. (Locke 1690, Bk IV, Ch. XVII, §20)

This seems to be a fairly clear account, but there are a number of important points to notice. Locke does not use the word fallacy: throughout this section he refers to "sorts of argument" which are used "to awe" opponents, in order "to prevail". It is not at all certain then that Locke has in mind mistakes in reasoning, rather he is concerned with unfair practices, a conclusion which is borne out by

1 Ad hominem is now used to mean any attack on an opponent rather than his argument, a long way from Locke's idea of confronting "a man with consequences drawn from his own principles or concessions" (21.III), and ad verecundiam is applied to any argument which cites the opinion of a third party expert, far removed from the original tactic where, when an opinion is offered of someone "established in any kind of dignity, it is thought a breach of modesty for others to derogate any way from it" (19.I).

(C) Martin Hinton. Informal Logic, Vol. 38, No. 2 (2018), pp. 184-212. 
the use of "force to submit" in the passage above. Even more importantly, however, there is no mention of a lack of evidence or lack of knowledge. There is certainly no suggestion that the lack of evidence of proposition $p$ has been taken to prove its falsity. On the contrary, Locke clearly states that by argumentum ad ignoratiam he means the tactic whereby one arguer declares that his argument must be accepted if his opponent has not a better one. In certain cases of practical reasoning, that may be considered fair-equating to the familiar move: "Have you got a better plan?" In other types of argument though, it appears to be a case of shifting the burden of proof, making a claim and not offering any evidence for it, leaving one's opponent at a loss for words.

Under Locke's definition, then, arguments from ignorance have nothing to do with arguing from a lack of evidence to a negative conclusion. In fact, his argumentum ad ignorantiam is a fallacy of unfair burden of proof shifting, something quite different. What Locke is discussing are arguments which break the second rule of van Eemeren and Grootendorst's pragma-dialectical guidelines for discussants: "whoever advances a standpoint is obliged to defend it if asked to do so" (1987, pp. 285). Indeed, it is reasonable to say that Locke's discussion of argumentational practice is the forerunner of the pragma-dialectical approach rather more than a step in classical fallacy theory, as he seems much concerned with what types of arguments might be considered "good-form" in a debate.

One reason why it is important, if unoriginal, to point to these differences is that in his own discussion, Walton sometimes uses the name of the argument form to refer to all three types and at other times concentrates on the presumptive argument. It will be necessary when examining his work below to bear that in mind.

The focus of this paper is on argument from ignorance as a form of informal, defeasible reasoning. That it is a deductive fallacy to "prove" that " $p$ is true" from an absence of information about not$p$, seems quite straightforward, and is a matter for formal logicians; and the fair placing of the burden of proof between parties is, while an essential part of good argumentational practice, outside the scope of the present work. What is of most interest here is to establish schemes and guidelines by which we are able to divide the uses of certain modes of argumentation into those that are reasonable 
and provide strong arguments, and those that are somehow flawed and lead, at best, to weakly supported conclusions.

\section{Walton's ad ignorantiam}

Researchers who have attempted to delve more deeply into the nature of arguments from ignorance have made a number of suggestions as to how they should be considered and in what ways our understanding of them might be improved and, indeed, embellished. As indicated above, these attempts have at times caused confusion due to a lack of clarity as to exactly what was meant by an argument from ignorance, and to a degree of over-ambition in the inclusion of more argument forms under the umbrella of ignorance then is, perhaps, justified. This section will concentrate on the writings of the well-known authority on fallacies and schemes, Douglas Walton; and the next on more recent work by A.J. Kreider.

Walton's writing on the argument from ignorance covers more than 30 years, including one full-length book treatment (1996a). It would not be surprising to find that his views had changed during that period, however, although there are some variations in the exposition of his ideas, the most contentious point was there at the beginning and has survived. In the 2008 opus Argumentation Schemes (Walton, Reed \& Macagno) there is a sub-scheme listed under arguments from ignorance and entitled "negative practical reasoning" (2008, pp. 327). This scheme looks rather different from the main one and, at first glance, seems to cover a completely different type of argument. Its inclusion can be traced to Walton's very conception of what presumptive reasoning is and, I argue, a certain equivocation on what arguing from ignorance is taken to mean. In Walton's defence, however, I shall show how, on a careful reading of his work, this equivocation does allow for a degree of internal consistency, despite its being difficult for others to accept.

In his earlier work, Walton (1985) gives a definition of argument from ignorance by citing two examples: one standard one, that ghosts have not been proved to exist, therefore, they don't exist; and a rather different one, about how to handle a gun at a firing range. Although it is true that: "If you try very hard to prove something and fail, it doesn't necessarily follow that what you tried 
to prove is false", in the case of ghosts, he argues, "it could be reasonable to operate on the presumption that they don't exist" (Walton 1985, pp. 266). Walton is clear from the beginning, then, that there are non-fallacious uses of the argument. The second example, however, is quite different. On the topic of firearms, Walton claims that: "If you don't know that a gun is not loaded, it may be prudent to provisionally assume that it is loaded" (1985: 266). As practical advice, this seems very sensible. Indeed it is usual for those handling such weapons to avoid pointing them at other people, even when they are very confident that the gun is not, in fact, loaded.

There is, however, a world of difference between what is "prudent" and, therefore, reasonable as an action, and that which it is reasonable to presume to actually be the case. It is reasonable in the sense of prudent not to bet one's entire fortune on black at roulette. It is not, however, reasonable to presume that black will not win, given that the odds of its doing so are almost even. Indeed, even in cases where it is reasonable to presume a particular circumstance to be the case, in the absence of conclusive evidence, it may still be reasonable to act as though it were not the case whenever the consequences of one's being wrong are sufficiently severe. Even though I remember removing all the bullets from my gun, I still don't point it at someone else and I certainly don't pull the trigger whilst doing so, just in case, out of prudence.

This second type of argument which Walton wants to include as an argument from ignorance appears to be a variation on Pascal's wager (1670 [1958]), where we are encouraged to believe in God because the negative consequences of being wrong by not doing so, going to Hell, far outweigh any negative consequences of being wrong by believing. Pascal's argument and the many responses to it also turn on the ambiguity of the word 'reason'. In section 233 where he discusses the wager, he first notes that on the question of the existence of God: "Reason can decide nothing", indeed, every human must "renounce reason to preserve his life". And yet it is clear that he is persuading the reader that it is in some pragmatic sense reasonable to wager that God exists. A large part of the criticism aimed at Pascal was that this doctrine would lead to false be- 
lief: that a precautionary reason to believe in God, was not a real reason to think He actually exists.

When Walton repeated this position in another paper on the same topic (Walton 1999a), he used the examples of the possibly loaded gun and a thorough FBI investigation which turns up no evidence, as occasions when a non-fallacious ad ignorantiam inference can be made. In his assessment of this work Wagemans (2003) finds the same differences of reasoning in these examples which were noted above. He expresses this in terms of two concepts of reasonableness: the geometrical and the anthropological, where the former is related to logical connections and the latter to community norms. These relate to the two criteria that he believes Walton is applying: the criterion of positive knowledge and the criterion of bad consequences. The criterion of positive knowledge covers the "evidence would have been found" premise which is needed for the FBI to conclude that their suspect is not actually guilty, whereas the criterion of bad consequences, obviously enough, cautions us that in the absence of evidence we should act as though the most dangerous circumstance were true and take appropriate precautions.

Wagemans is quite correct in his analysis; and yet it is, in a sense, irrelevant to Walton's actual position. By looking at his writing published in between the two papers we can form an understanding of how he comes to consider the two examples to be so closely related. In his 1996 book Argumentation Schemes for Presumptive Reasoning, Walton notes that:

The analysis of argumentation schemes is very much affected by the recognition of practical reasoning as a distinctive type of reasoning, as distinguished from what might be called theoretical or discursive...[it] is directed to choosing a prudent course of action for an agent that is aware of its present circumstances. (1996b, pp. 11)

He goes on to contrast this with discursive reasoning, which is concerned with "weighing reasons for and against the truth or falsity of a proposition" (1996b, pp. 11). There are two important points to draw from this passage: one is that Walton is suggesting that his argumentation schemes are, at least in the main, meant to be applied in practical situations and not in the determination of 
truth and falsity, something which is often overlooked by researchers commenting on them, and perhaps sometimes by Walton himself. Second, Walton makes it clear that prudence is a central tenet of what this type of reasoning is for. From this we can conclude that the fact that one of his examples seems to lead to belief formation and the other only to an application of a principle of prudence is of no significance: it is not relevant for Walton what beliefs we form on the basis of the argument, only how we act.

Since Walton refers to these schemes in the title of the book as being for "presumptive reasoning", it is also worth an extended look at what he means by that. Walton defines it thus:

Presumption $[\ldots]$ is an essentially pragmatic notion which enables a discussion or an action to go ahead on a rational, even if provisional basis, where access to evidence which would definitely resolve a question is lacking. For even if the evidence is insufficient there may be enough of it to indicate the wisdom of a provisional course of action in given circumstances. Such a procedure can be rationally justified if, for practical but good reasons, a burden of proof can be set to tilt the resolution of the issue in one direction or the other. (1996b, pp. 38)

One such occasion would be a tilting of the burden of proof towards a safety-first approach, and again Walton gives the example of the firing range. He concludes the passage: "The ad ignorantiam nature of this type of presumptive reasoning is quite clear. If you do not know that the weapon is unloaded then you infer that it is loaded" (1996b, pp. 38). (The exact same sentences appear in 1996a, pp. 210).

There are two problems with this final point. First, the ad ignorantiam nature of the reasoning is far from clear, and, second, it isn't true that we infer that the weapon is loaded-we infer that it might be loaded and act accordingly. Walton himself seems to confuse the distinction he made between reasoning as to what is the case and reasoning as to how to act: the action has become the inference, which strikes me as a problematic notion.

There is also confusion on the first point. Walton notes just three pages earlier that: "It seems then that the argumentum ad ignorantiam is sometimes a reasonable kind of argumentation, and when it is, it is because it is somehow based on presumptive 
reasoning - an inference based on a presumption about what one would know if it were the case" (1996b, pp. 35). There is no sense in the loaded-gun example of "what one would know" - the whole point is that there is no way to tell if a gun is loaded from a distance - one wouldn't know if it were loaded and one wouldn't know if it weren't.

Walton, then, appears to use the term 'ad ignorantiam' with two very different meanings within three pages. On page 35 he defines it in a fairly standard way as pertaining to expected knowledge, but on page 38 he takes it to mean any type of argument where knowledge is somehow incomplete. It is telling that in the latter section, he goes on to mention appeals to expert opinion, tradition and popular belief as similar cases, suggesting he considers all presumptive, defeasible argument types to have an ad ignorantiam nature to them. As J. Anthony Blair puts it: "he sees presumptive reasoning in general as a kind of reasoning from ignorance" (Blair 1999, pp. 339).

If that is the case, is there any justification for considering "negative practical reasoning" to be a sub-type of argument from ignorance, but not the others? There is, in fact, one way in which such cautionary arguments are linked to "absence of expected evidence" arguments, and other presumptive reasoning schemes are not. In both cases it is the lack of evidence itself that is taken to be the significant factor. In other arguments, while we acknowledge that the evidence is incomplete, we focus on what we have: in these two cases our reason for reaching the inference we reach is that very lack. The fact that the evidence is not available is significant in choosing our course of action, rather than an obstacle to doing so. That conclusion, however, must be teased out of Walton, as it isn't made explicit.

Elsewhere, Walton suggests that what the gun example has in common with other arguments from ignorance is that it "goes from a premise of non-commitment to a proposition $A$ to a conclusion of commitment to not- $A$ " (1988, pp. 238). This presumably means that we move from non-commitment to the premise the gun is unloaded, to a commitment that it is loaded. Although, in fact, we only move to a commitment to act as though the gun were loaded. 
In this way, then, Walton's inclusion of negative practical reasoning as an argument from ignorance does appear to be internally consistent within his system: all presumptive reasoning involves a degree of ignorance - that's why it's only presumptivebut only that reasoning which relies on that ignorance for its conclusion is actually to be referred to as argumentum ad ignorantiam. All of which relies on the conception of presumptive reasoning as applying more or less exclusively to practical reasoning. If we try to apply these schemes to "theoretical" or "discursive" argumentation, then the differences between them become clear: in one a lack of evidence leads to a belief in a state of affairs, and in the other no such belief is formed and the lack of evidence leads to the mere assumption of a state of affairs for pragmatic reasons.

Confusion may arise, however, over Walton's views as it is not always clear if he is considering the argument in this light. In other work he discusses ad ignorantiam arguments which are clearly linked to belief formation, not to practical reasoning, and here too there are some concerns worth investigating. In one paper (1992), he describes what he considers to be non-fallacious arguments from ignorance. He begins by considering four examples, all of which rely on de Cornulier's principle of epistemic closure, "it is not the case that I know it is raining; therefore, it is not raining" (de Cornulier 1988, pp. 182), i.e., that if the knowledge base can be considered to be complete then the lack of any evidence of $p$ within that base can be taken as good reason to believe not- $p$. Although they are portrayed as different cases, three of them are nonfallacious arguments for not- $p$ based on that principle. The remaining example is a negative one: it says that since we know some of Aristotle's work is not extant, we cannot assume that he didn't discuss certain matters just because they are not discussed in the works we have. The principle upon which this argument works is exactly the same as the other cases, but used in reverse: here, we know that the knowledge base is incomplete, and in that situation we cannot draw the conclusion not- $p$, even though $p$ is not supported by what evidence we do have. Walton quite correctly points out that in all such cases, the conclusions are "subject conditionally to 
future evidence that may arise in the future investigations or argumentation" (1992, pp. 383).

However, in this section Walton refers to this form of reasoning as "a kind of practical reasoning [...] which goes forward in argument as licensing a tentatively reasonable conclusion" (1992, pp. 382). It isn't at all clear in what way a belief in whether or not Aristotle discussed a particular issue can be considered "practical" rather than "theoretical" or "discursive". He further adds to the confusion by explaining that: "It is an epistemic type of argument, but in many cases the conclusion one is warranted to infer is not a knowledge claim" (1992, pp. 384). "Practical" now seems to mean something which can be used in the practice of argument; but how that differs from discursive argumentation, which is also carried on in practice, is hard to say.

Walton then notes that the argument "is not exclusively an inconclusive type of presumptive argument, nor is it generally equivalent to presumptive reasoning as a type of argumentation" (1992, pp. 385) and goes on to give two differing argumentation schemes for epistemic argumentum ad ignorantiam: one where it is a deductive inference grounded in a knowledge base that is known to be closed, and the second where it is a presumptive argument grounded in a knowledge base which can, within the given context, be considered sufficiently closed. The second scheme follows the general agreement on what arguments from ignorance do. However, I find this first characterisation neither helpful nor necessary. Consider the following example: "I have here a list of all the FIFA World Cup winners since the competition began. Poland is not on that list. I conclude that Poland has never won the FIFA World Cup." There is no sense in which that could be considered an argument from ignorance, as there are no missing data: the arguer is not ignorant of any relevant information at all. The fact that the name Poland is "missing" from the list is not somehow equivalent to the date 1982 not having a name next to it and thus the 1982 winners being "missing". Walton's first deductive argumentation scheme is better considered as an expression of the rule of logic upon which, at a certain remove, arguments from ignorance rely. No purpose is served by claiming that to state that "all the true propositions in a given world are $q, r$, and $s$, therefore, $p$ is not a 
true proposition in that world", is an argument from ignorance. Indeed, such reasoning cannot even be considered an argument from lack of evidence, since all the evidence required to make a deduction is available. What is of great importance to arguments from ignorance, however, is that this model is the logical form that they somehow mirror, but don't quite match up to, precisely because not all the evidence is available.

Oaksford \& Hahn, on the other hand, accept such cases as arguments from ignorance "as they do have the same underlying form" and further claim that "In the real world, the closed world assumption is rarely justified so it is not reasonable to assume that if $A$ were true this would be known" (2004, pp. 77). This is an unsupported empirical claim that I see no reason to agree with. When I ask my students to sign a list of attendance, I am justified in assuming that anyone not on the list did not attend the class; when I watch the team line-ups being presented on television just before the match I am justified in assuming that anyone not mentioned will not be starting the game. Such situations, where all the relevant facts are available and the absence of one item from those facts can be taken to mean its actual absence, seem to me extremely common. As to the underlying form, I think that's a controversial point: very many arguments have something in common in their form. The difference between the premises " $A$ is not known to be in the relevant data set" and " $A$ is known not to be in the relevant data set" seems very significant to me-enough to suggest a different kind of argument.

One might expect that a study of Walton's previously-mentioned 1996 book-length treatment of this subject would clear up some of the difficulties and apparent inconsistencies of the various papers. However, it is doubtful whether the greater length provides much clarity. Indeed, in many sections, the contents of the book simply reproduce what can be found in other papers and other chapters contain much about the history of the argument and its uses in realworld reasoning.

In a section entitled "Three Types of Argument from Ignorance" (1996a, pp. 143), for instance, Walton lists those types as epistemic, inductive and dialectical: a trio dating back to his earlier work with John Woods, but not mentioned in the intervening work. The 
discussion of the three is far from clear, and Oaksford \& Hahn sensibly rephrase them as referring to "shifting the burden of proof, epistemic closure, and negative evidence" (2004, pp. 76). The epistemic type relates to epistemic closure, the inductive type to inferences based on negative evidence, and the dialectical type to shifts in burden of proof. This is an attempt to include the three uses of the ad ignorantiam name which were referred to in the disambiguation above in one description: still there is clearly no place in this list for negative practical reasoning arguments.

The "dialectical", "burden of proof" form is close to the argument as expressed by Locke. Here, Walton explains that "the form needs to be modeled as an account of the use of the argument in a context of dialogue for some communicative purpose" (1996a, pp. 151), which seems fair but is clearly dealing with a different type of fallacy from the other forms.

On the epistemic variant, which he now proposes to call "the knowledge-based type of ad ignorantiam argument", Walton claims: "It can have a deductive form [...] as well as a presumptive form" (Walton 1996a, pp. 150). The deductive form being apparent when there is real closure and the presumptive being necessary when there is only partial closure. The strength of the inference obviously depends upon the degree to which we believe that closure to be complete. Earlier though, he had stated that "defining the argument from ignorance is trickier than one may have initially thought. Such an argument is never an argument from total ignorance (a complete absence of knowledge) but is always a mixture of knowledge and ignorance" (Walton 1996a, pp. 139). This suggestion would seem to rule out the deductive form, and its status remains somewhat unclear.

The principle difference between epistemic closure cases and "induction from negative evidence" seems to be the nature of the evidence and the possibility of ever closing the data set, but more of that in the general discussion below. For Walton, there seems to be little difficulty in uniting such cases and the presumptive epistemic argument form under one scheme.

That scheme, for what Walton calls the "basic type" (1996a, pp. 252) of argument from ignorance, in the slightly simpler 2008 version, runs thus: 
Major premise: If A were true, then A would be known to be true. Minor premise: It is not the case that A is known to be true.

Conclusion: Therefore, A is not true. (Walton et al. 2008, pp. 327)

Clearly the major premise here does not apply to cases of negative practical reasoning, and there are questions over the phrase "be known to be true" - not least, why would it be known and by whom would it be known? The alternative scheme I draw below avoids this issue. It is also worth noting, as Michael Wreen points out that "there's absolutely nothing about that type that requires or even faintly suggests that ad ignorantiam should be construed dialectically" (Wreen, 2000, pp. 55). Walton's conversion to the dialectical approach is a subject beyond the scope of this paper, but this comment from Wreen reveals another inconsistency in this period of Walton's work: the importance of the dialectic is referred to throughout, but its influence in the final conclusions, the argument schemes he draws up, is not always particularly apparent.

To conclude the discussion of Walton: I have shown that, alongside a good deal of important clarification, he has introduced two unnecessary and unhelpful elements to the debate. First, there is no need for an argumentation scheme for the deductive inference of not- $p$ in circumstances of epistemic closure, where all relevant data are known to be available, under the title argumentum ad ignorantiam, as this serves only to confuse the issue. Second, one group of cases, exemplified by the possibly-loaded gun, does not deserve to be accepted under the appeal to ignorance umbrella, as it is not an attempt at a persuasive argument, merely a principle of precaution. While this may be, in a sense, consistent with the account Walton sometimes expresses, his varying use of the term 'argument from ignorance' has made it difficult for other scholars to pin down exactly what his view is: taking his writing on the subject as a whole, it is hard to say to what extent he considers all presumptive reasoning to be a form of appeal to ignorance or what exactly he believes the relationship between the "epistemic closure" and the "prudent action" types of such arguments to be. 


\section{Kreider's Tiger in the Room}

Although the work discussed above has been around for some years, it will become clear in the final section why it was necessary to review it, and particularly why the cases based on what Wagemans called anthropological reasoning had to be separated from other forms of the argument. In a far more recent paper A.J. Kreider (2016) discusses the argumentum ad ignorantiam as a case of abductive reasoning: that is, as inference to the best explanation.

Kreider begins by noting that, as is usually the case in informal fallacies, the key issue is to find a way to tell the difference between fallacious and non-fallacious uses of the argument. Two possible non-fallacious groundings are given: the "context dependent pragmatic considerations", relying on consequences, which we have just banished from the discussion above, and the possibility that "some instances of what look like ad ignorantium [sic] are really enthymemes with hidden premises concerning expectations of evidence" (Kreider 2016, pp. 75). This is an odd characterisation as it clearly begs the question, since saying that enthymematic cases merely "look like" ad ignorantiam arguments is tantamount to saying that they are not in, fact, ad ignorantiam arguments, where other researchers clearly consider them to be so.

Kreider raises two objections to treating appeals to ignorance as enthymemes, both of which can be dealt with quite swiftly. First, is the worry that by attributing a missing premise to the speaker, we are presuming too much about that person's reasoning. This point is not expanded upon, but presumably what Kreider means is that arguers may often make statements such as "you can't prove God doesn't exist, so he must do" without implying the counterfactual premise that if He didn't, you would be able to prove it. Perhaps I simply have more faith in my fellow man, but I think this is rather unlikely. I suspect that in any such case if one were to question why the lack of evidence against a proposition was evidence for its truth, the response would be to provide the missing premise. This empirical question is of little importance anyway: anyone wishing to maintain that $p$ is simply true on the basis of no evidence to the contrary is committing a deductive fallacy. If the aim of our investigation is to allow us to ascertain when the appeal to igno- 
rance is justified and when it is not, it is to our advantage to treat all such appeals as enthymemes, especially since we cannot see into the mind of the person putting forward the argument.

Kreider's second objection is that,

If we take the enthymeme route, we could implausibly apply it for all instances of apparent ad ignorantium [sic] [...] which would yield the result that appeals to ignorance may not be errors in reasoning at all. Rather, the strength of the arguments in question will reduce to the reasonableness in accepting the premises; particularly those concerning the expectation of evidence (2016, pp. 75-76).

Kreider does not seem to grasp the difference between formal and informal logic here. Considering the "reasonableness in accepting the premises" is basically what informal logicians do, so it's hard to see why this is such a problem.

The dismissal of the enthymematic construal of appeals to ignorance because of their basis in reasonableness rather than deductive power would not matter if Kreider were only interested in formal logic. However, the main purpose of the paper is to develop a theory of fallacies as cases of abductive reasoning. Kreider bemoans the portrayal of argumentum ad ignorantiam as a deductive fallacy in logic textbooks but then considers non-deductive examples as not real cases of the argument.

In the more constructive part of the paper, Kreider gives an introduction to what is meant by abductive reasoning and then makes the following statement:

Returning to ad ignorantium, while it is certainly true that it does not follow from a lack of evidence that $p$, that it is false that $p$, there will be many cases where the best explanation for the lack of evidence for $p$ is that it is false that $p$. Of course, in such cases there will always be competing explanations for the lack of evidence, but they won't be reasonable explanations, and can thus be dismissed. What is the best explanation for the fact that there is no evidence of a tiger in the room? It is, of course, that there is no tiger in the room. The possibility that there is an invisible, silent tiger in the room can be ignored. (Kreider 2016, pp. 78)

The question that this leaves open, of course, is this: why is the lack of evidence of a tiger best explained by the absence of a tiger? 
To which the answer can only be: because if there were a tiger, we would expect evidence of one. Thus, we are brought back around to the starting point of an enthymematic argument. This objection applies to every attempt to impose abduction as characteristic of informal fallacies: in the example of ad populum, Kreider suggests that the best explanation for lots of people believing something to be true is that it is, in fact, true. That, however, is only the best explanation if one accepts the reasoning that so many people are unlikely to be wrong: the very premise on which the ad populum argument as traditionally understood is based.

The fundamental error Kreider makes is to see abduction as a type of argument rather than a category of reasoning. It is never a good argument to simply say "it's true because it's the best explanation". We must still put forward reasons as to why it is a good explanation, and test whether we or anyone else, can come up with better reasons for a better one. Abductive reasoning allows us to accept conclusions based on arguments which are weak, in the absence of better ones, just as presumptive reasoning allows us to accept conclusions which are based on arguments containing the presumption of the truth of certain premises. In a sense, Kreider is right: informal reasoning is often abductive, but pointing that out does not move the understanding of argument structures such as ad ignorantiam forward at all. The question of importance is: Why is it most reasonable to assume not- $p$ in some cases where there is no evidence of $p$ ? That we cannot know not- $p$ deductively has already been established. Kreider has told us that much informal reasoning is not deductive: not a surprising assertion.

\section{A simple structure}

In this section I set out a simple argumentation scheme complete with critical questions and illustrate its use with common examples. I also defend it against criticisms already to be found in the literature. I shall assume that deductive inferences from closed world situations where all relevant data are known are not to be included. I shall also assume that the scheme should be viable for reasoning about beliefs and not only actions, and therefore reject Walton's 
negative practical reasoning arguments which are based upon the absence of a belief leading to a certain action.

Arguments from ignorance are syllogisms, most often expressed enthymematically with a hidden premise concerning the expectation of evidence. The presumptive argument that no evidence of $p$ means not $p$, can be more fully developed as:

1. There is no reliable evidence available to us of $p$.

2. It is reasonable to expect that if $p$ were true, there would be reliable evidence available to us of $p$.

Therefore: $p$ is not true.

Alternatively,

1. There is no reliable evidence available to us of not- $p$.

2. It is reasonable to expect that if $p$ were not true there would be reliable evidence available to us of not- $p$.

Therefore: $p$ is true.

It is important to note that this is a scheme setting out a potential non-fallacious use of the argument. Other less respectable structures could easily be suggested such as: If there is evidence of $p$ then $p$ is true, there is no evidence, therefore $p$ is not true, which would be a simple case of denying the antecedent. The conclusion of the argument is, naturally, defeasible and the form should be understood as operating within the presumptive reasoning tradition.

The two premises of the syllogism lead naturally to two possible critical questions:

1. Is such evidence, in fact, not available to us?

2. Is it reasonable to expect such evidence to be available to us?

The first of these is partly an empirical question, either evidence exists, or it does not, but also partly one of judgment about the reliability of any available evidence. It is not hard to imagine cases where large amounts of statistics or "expert" opinion are put forward by one disputant but rejected by another on grounds of reliability. The question could be sub-divided into three questions: Is there evidence? Is it reliable? Is it available to us? 
The second critical question will, in most cases, be the key issue at stake in the argument. If we cannot realistically expect evidence to be available, then its absence is not in any way remarkable. One obvious objection that might be raised here is that the argument scheme does not provide any method for resolving this second question, and, very often, the acceptability of an appeal to ignorance will rely wholly on its resolution. To object thus, however, is to misunderstand the business we are engaged in: no scheme can tell arguers if the argument is a good one or a bad one. The scheme leads to the questions, and it is these questions that show disputants how to usefully continue their discussion. The arguer who employs this scheme of argument is obliged to show why the answers to the two questions are "yes" and "yes", the opponent will try to show that at least one answer is "no". The scheme itself cannot decide individual cases.

Before considering any further possible objections, it would be well to look at how the scheme works with some well-known examples. In the examples that follow, the arguments as formulated assume a second unexpressed premise.

Argument: There is no evidence of God's existence, so God doesn't exist.

In this case, both premises are very controversial. Anyone who is convinced by the Design Argument will obviously deny the first premise and state that the universe itself is evidence of God's existence. Also, the believer can point to the myriad testimonies of those who claim to have had religious experiences. So, one way for this argument to progress is through a discussion of the value of that apparent evidence. Alternatively, disputants may consider whether it is reasonable to expect evidence, presumably of an empirical kind, of the existence of a supernatural being to be available to us in the natural world.

When the argument is employed in reverse, the situation is clearer:

Argument: There is no evidence that God doesn't exist, so God exists. 
Here, the first premise is hardly worth discussing, and the second, hidden premise, can be easily dismissed. That it is reasonable to expect evidence of the non-existence of a supernatural being to be available to us, is a position unlikely to stand much consideration. This is likely to form a pattern: it is easier to convince others that the existence of an object would leave evidence than that the nonexistence of an object would. It is not impossible to find plausible examples, however:

Argument: There is no evidence our class is not going ahead, so our class is going ahead.

If all the students agree that there has been no e-mail from the teacher and no notice put up on the board, then the first question is answered. If they also agree that, according to usual practice, it is reasonable to expect that there would be evidence of the class's not going ahead if it were in fact not going ahead, then the second premise is also accepted, and the argument is sound. Such examples show how grammar can lead us down blind alleys if we are not careful: a negative is often a positive in disguise, and the argument could simply be rephrased as "there is no evidence our class has been cancelled, therefore it has not been cancelled". Suddenly we are looking for evidence of a something - the cancellation - not a nothing.

If the two sides can agree on the lack of evidence, then the degree to which arguments from ignorance may be considered fallacious depends on how reasonable it is to expect evidence. In the case of aliens, it is hard to argue that, given the enormity of the universe, evidence of their existence can be expected to have reached us if they do exist, but in Kreider's tiger in the room example, it is obvious that it is very unlikely there would be no sign of the animal. Weighing these probabilities is the job of the disputants, and it is clear that many cases will fall in the middle and generate real debate.

There is another class of cases where the second premise is so obvious as to be functionally redundant: some facts provide evidence of themselves. We can be sure that it is not raining if there is no evidence of rain: rain is its own evidence. There seems no reason to debate, in the case of rain, whether it is reasonable to expect 
evidence. So, the following is perfectly acceptable if the first premise is true:

Argument: There is no sign of rain outside, so it is not raining.

Here the conclusion could obviously be qualified for time and place constraints. Such cases may be considered examples of epistemic closure, as discussed above, but might be thought of as lacking the absolute logical certainty of a full list of true propositions from which to make a deduction.

One very well-known example of this type of reasoning in action concerns the hunt for weapons of mass destruction in Iraq after the US-led invasion had toppled Saddam Hussein's regime. After "an intensive 15-month search by 1,200 inspectors from the CIA's Iraq Survey Group" found little of interest, then British Prime Minister, Tony Blair stated "I have had to accept that the evidence now shows that there were not stockpiles of actual weapons ready to deploy" (The Guardian, 7/10/2004). Despite his insistence before the invasion that such weapons were ready and available for use by the Iraqi government, Blair's argument seems to be: no evidence of WMDs in Iraq has been found, therefore there were no WMDs, a conclusion which can only be justified by adding the hidden premise: it is reasonable to expect that if there were WMDs in Iraq, 1200 inspectors working for 15 months would have found evidence of them. This interpretation is supported by the fact that Blair was so convinced of, and staked so much political capital on, the existence of such weapons that he must have considered the failure of the inspectors to find them an extremely strong reason to change his viewpoint: he no longer even considers the possibility that they might not be fairly expected to have found evidence within that time-frame.

\section{Further discussion}

There are three issues which this section will discuss further: the advantages of the suggested scheme, possible problems with that scheme and some thoughts on the subject of epistemic closure and how exactly it affects the degree of confidence we have in arguments from ignorance.

(C) Martin Hinton. Informal Logic, Vol. 38, No. 2 (2018), pp. 184-212. 
The advantages of the proposed scheme over Walton's version are illustrated by the examples in the section above. By referring specifically to available evidence rather than the somewhat vague what might be "known to be true", the ensuing debate has more direction and a clearer empirical nature. In cases such as those concerning deities or other supernatural phenomena, disputants can hardly be expected to accept what believers "know to be true", and it would be very hard to discuss the issue with someone who claims "I just know that it's true" without offering any justification. Concentration on evidence avoids such difficulties and makes it clear that in a dialogue, only evidence available to both parties is of relevance. It is quite possible that Walton meant "known to be true" to be understood as "generally known", but that also brings with it more complications. Available, reliable evidence is clearly the key factor. In other respects the two approaches differ only in the lack of any superfluous sub-schemes in my account.

Turning to possible criticisms, both Walton and Kreider raise doubts about accounts that rely on an "evidence would be available / we would know" premise by questioning the use of conditionals in the argument scheme. Kreider writes of such premises: "They are subjunctive conditionals (we would have found. . . ). Such conditionals are notoriously difficult to evaluate, and identification of instances of ad ignorantium don't seem to require well-considered views of the truth conditions of such premises" (2016, pp. 76). This statement seems to be wrong on two points: first, in many cases, such as the tiger example, the conditional is not at all hard to evaluate-if there were a tiger there would be evidence. Second, a philosopher's understanding of truth conditions for conditionals may not be necessary to evaluate ad ignorantiam arguments, an understanding of the truth of them is the crux of the matter and doesn't strike me as particularly difficult to reach in a large number of cases. Those where it is difficult to reach will remain controversial.

Although Walton uses a conditional in his scheme he worries that, as usually understood, it "presupposes the falsity of the antecedent of the first premise, the very proposition the argument aims to have as its conclusion" and explains that in this case: "What the 'if ... then' says is that if the antecedent is true (acceptable), in normal circumstances, but subject to exceptions, the consequent is also 
true (acceptable)" (1999b, pp. 58). I'm not sure that this explanation is really necessary: although the phrase "if $p$ were true" does seem to imply that $p$ is not, in fact, true, the truth or otherwise of $p$ is incidental to the truth of "if $p$ were true then $q$ would be true". The arguer employing this "counterfactual" is not committed to the proposition not- $p$, that $p$ is counter to the facts, and is not, therefore, begging the question. There seems to be conflation here of the normal use of such conditionals in statements like "if I were an alien, I would...", and the type of reasoning which is most elegantly expressed in such a conditional, but could equally well be expressed differently, as below. Within the context of presumptive reasoning, the caveats which he attaches - "in normal circumstances"- are part of the general framework anyway.

In any case it is perfectly possible to rephrase the argument scheme without using a conditional at all.

1. There is no reliable evidence available to us of $p$.

2. In situations where $p$ is true, such evidence of $p$ can reasonably be expected.

Therefore: $p$ is not true.

The grammatical device of the counterfactual is just that; it is not essential to the reasoning process. Restating Kreider's example:

1. There is no evidence of a tiger in this room.

2. One expects tigers in rooms to leave evidence.

Therefore: There is no tiger in the room.

One objection to this might be that the second premise is either unknowable or simply begs the question. That worry would be better brought out by a different example:

1. There is no evidence of the existence of God.

2. One expects Gods to leave evidence.

Therefore: There is no God.

It should be noted, of course, that the use of a simple statement or a conditional makes no difference here: the claim that God would leave evidence is no easier to show than that Gods do leave evidence. This, however, is a problem specific to the case of "unknowable" entities such as deities and is not intrinsic to the argu- 
ment structure. The same can be said of the begging the question doubt. Premise 2 above might be seen as begging the question in a general debate about the existence of God, where one disputant would like to maintain that such evidence is not to be expected, but it is not begging the question within the confines of the ad ignorantiam argument.

Walton also worries that the argument might appear to assume the form of a modus tollens when he believes we should "think of such arguments as being abductive and defeasible in nature". He stresses that "the type of inference used in the argument from ignorance, while it looks like a modus tollens kind of inference in its broad outline, is not literally the modus tollens inference that we are familiar with in deductive logic, where it is typically modeled using the material (truth-functional) conditional" (1999b, pp. 58). Again, however, this point seems to be directed at those who are unfamiliar with the distinctions made in Walton's thinking between standard logic and presumptive reasoning - the structure is that of a modus tollens, but it's a presumptive modus tollens and that needs to be borne in mind in the understanding of all presumptive argumentation.

The last objection that I shall consider is that arguments from ignorance as I have defined them are not really based on ignorance at all, but rather on a degree of knowledge. In discussing cases that would fit my definition, Copi and Cohen state that "we rely not on ignorance, but upon our knowledge, or conviction, that if the result we are concerned about were likely to arise, it would have arisen" and add that the ad ignorantiam fallacy is "the mistake that is committed whenever it is argued that a proposition is true simply on the basis that it has not been proved false" (1990, pp. 93). This strikes me as incoherent. I'm not sure what it would mean to make any claim based purely on ignorance, without the employment of any knowledge, but certainly under their own definition, one must know that "it has not been proved false", so the argument here is not entirely based on ignorance either. Clearly these comments pertain to the use of ad ignorantiam as a deductive fallacy anyway, not as a presumptive argument form, which we have already seen to be a very different case. 
The principle of epistemic closure has been referred to throughout this discussion, and there are a number of important conclusions which should be brought to the fore concerning its relevance to arguments from ignorance, which are not discussed by Walton. As has been argued above, in situations where there is complete and genuine closure and where all possible relevant data are available, there does not seem to be any room for "ignorance". While opinion is divided among researchers on this matter, I would not categorise this type of deductive inference as an argument from ignorance.

In other situations, where certainty of closure has not been achieved, there are three different possibilities: situations where some relevant data are known to be missing, situations where some data may be missing, and situations where there is no obvious limit to the relevant data and full-closure could never be reached. The strength of an argument from ignorance, and, therefore, it's likelihood of success, depends not only on what proportion of the relevant data has been collected and how hard data have been looked for, but also which of these three situations pertains. The third type, where full-closure is not possible, will include all attempts to prove a negative by looking for signs of its existence. In medical research, for instance, before a new drug can be approved it is tested for possible harmful effects. It is clear that in such cases fullclosure could never be achieved, as that would involve testing not just every living human, but all future humans as well. Every jurisdiction must, therefore, set a minimum level of testing to be completed before general use can begin. No drug can ever be said to be perfectly safe because the data set is never complete, but it can be safe enough.

Similar reasoning is employed when we use arguments from ignorance to deny the existence of gods or ghosts. It is hardly possible to prove the non-existence of such an entity, but we may decide that our own experience and the conclusions of modern science are enough to outweigh centuries of unreliable superstition. This might lead us to conclude that such instances, where a dataset is necessarily incomplete constitute grounds for the "real" argument from ignorance. 
In the other two situations the argument seems, intuitively, less persuasive. To return to the example of the list of World Cup winners, if there is a blank space beside one or more of the years in which the competition was held, then it seems unlikely we would accept, even as a presumptive inference, the statement that "Poland have never won the World Cup, because they're not on the list". When the dataset is incomplete and it is known that the missing data are relevant, then an argument from lack of evidence looks very weak indeed. This is the case in Walton's Aristotle example, but he only comments that the argument is a fallacy because "our list of the topics that Aristotle wrote on, in the subject of rhetoric, is incomplete" (Walton 1992, pp. 382) without further explanation.

Cases where some data may be missing are even more difficult to assess. We are ignorant as to the degree of our ignorance and are forced to speculate on evidence that may or may not exist. In practice, we are forced to either regard our data as complete, and proceed by deductive inference from there, or assume that they are incomplete and accept that an argumentum ad ignorantiam is the best we can do. I would suggest, therefore, that it is not enough to determine whether or not there is epistemic closure in a particular case: when there is not, we must also consider what type of lack of closure there may be.

\section{Conclusion}

This paper set out to achieve two goals: to provide a clear description of how arguments from ignorance can work as presumptively valid argument forms, and to discuss a number of issues raised by the discussion of such arguments.

In order to complete the first task it was necessary to disambiguate the various meanings given to the term argumentum ad ignorantiam, and then to examine the works of the best-known writer on the topic, Walton, and a more recent paper, that of Kreider, in order to highlight weaknesses in their accounts which might be improved upon. This discussion was followed by the presentation of my own approach to this argument form along with a description of how it works in practice. The scheme I outlined moves from a concentration on the difficult question of knowledge 
on to the more concrete basis of available evidence, and leads neatly to the two crucial points of the argument: is there, in fact, a lack of evidence, and is that lack of evidence, in fact, significant? The value of an argument from ignorance lies simply in this: that it notes a lack of evidence and states that that lack is meaningful.

The other conclusions reached along the way, however, may have wider resonance. The discussion of Walton highlighted the questions that his work leaves over the role of ignorance in presumptive reasoning in general and the degree to which his argumentation schemes have epistemic relevance and can lead to belief formation, rather than simply to actions. I argued that his inclusion of the argument from negative reasoning as a sub-type of the argument from ignorance suggests he is committed to the view that schemes are for practical reasoning, not epistemic belief formation (despite the existence of an "Epistemic Argument from Ignorance" (Walton et al. 2008) scheme), and that Walton reserves the term 'argument from ignorance' for any argument in which the statement of a lack of knowledge itself is an important premise.

The section discussing Kreider's paper illustrated that a reliance on abduction to allow us to avoid more rigorous patterns of reasoning simply won't work: for any conclusion to be considered the best, reasons why it is good will still need to be put forward, and those reasons will be subject to acceptance or rejection, just as much as presumptive arguments.

Finally, three types of epistemic non-closure were described along with how the way in which a dataset remains open may affect the perceived strength of arguments from ignorance when they rely on something approaching closure as a basis for their claims. This is an issue that certainly requires more consideration in future work.

\section{References}

Blair, J.A. 1999. Review: D. N. Walton, Argumentation Schemes for Presumptive Reasoning. Argumentation 13: 338-343.

Copi, I. \& Cohen, C. 1990. Introduction to Logic, 8th ed. New York: Macmillan. 
de Cornulier, B. 1988. Knowing whether, knowing who, and epistemic closure. In: M. Meyer (ed.) Questions and questioning. Berlin: Walter de Gruyter.

van Eemeren, F. and Grootendorst, R. 1987. Fallacies in Pragma- Dialectical Perspective. Argumentation 1: 283-301.

The Guardian. 2004. There were no weapons of mass destruction in Iraq. 07/10/2004.https://www.theguardian.com/world/2004/oct/07/usa.iraq1

Kreider, A. 2016. Informal fallacies as abductive inferences. Logic And logical philosophy, 25: 73-82.

Locke, J. 1690/1975. An Essay Concerning Human Understanding. Oxford: Oxford University Press.

Oaksford, M \& Hahn, U. 2004. A Bayesian approach to the argument from ignorance. Canadian Journal of Experimental Psychology, 58(2): $\quad 75-85$.

Tindale, C. 2007. Fallacies and argument appraisal. Cambridge: Cambridge University Press.

Pascal, B. 1670/1958. Pascal's Pensées. New York: E. P. Dutton \& Co.

Wagemans, J. 2003. Conceptualizing fallacies: The informal logic and pragma-dialectic approaches to the argumentum ad ignorantiam. In: Proceedings of the fifth conference of the International Society for the Study of Argumentation. F.H. van Eemeren, J.A. Blair, Ch. A. Willard \& A.F. Snoeck Henkemans (eds). Amsterdam: Sic Sat

Walton, D. 1985. New directions in the logic of dialogue. Synthese (63): 259-274.

Walton, D. 1988. Burden of proof. Argumentation 2: 233-254.

Walton, D. 1992. Nonfallacious arguments from ignorance. American philosophical quarterly 29(4): 381-387.

Walton, D. 1996a. Arguments from Ignorance. University Park, Pennsylvania: Penn State Press.

Walton, D. 1996b. Argumentation Schemes for Presumptive Reasoning. New York: Routledge.

Walton, D. 1999a. The appeal to ignorance, or argumentum ad ignorantiam. Argumentation 13: 367-377.

Walton, D. 1999b. Profiles of dialogue for evaluating arguments from ignorance. Argumentation 13: 53-71.

Walton, D. Reed, C. \& Macagno, F. 2008. Argumentation Schemes. Cambridge: Cambridge University Press

Woods, J \& Walton D. 1978. The fallacy of 'Ad Ignorantiam'. Dialectica 32(2): 87-99.

Wreen, M. 2000. Review: Douglas Walton (1995) Arguments from Ignorance. Argumentation 14: 51-56. 
Zarefsky, D. 2005. The study of effective reasoning. Chantilly, Virginia: The great courses.

(C) Martin Hinton. Informal Logic, Vol. 38, No. 2 (2018), pp. 184-212. 